\title{
Increased serum baseline tryptase levels and extensive skin involvement are predictors for the severity of mast cell activation episodes in children with mastocytosis
}

\author{
I. Alvarez-Twose ${ }^{1,2}$, S. Vañó-Galván ${ }^{3}$, L. Sánchez-Muñoz ${ }^{1,2}$, J. M. Morgado ${ }^{1,2}$, A. Matito ${ }^{1,2}$, \\ A. Torrelo ${ }^{4}$, P. Jaén ${ }^{3}$, L. B. Schwartz ${ }^{5}$, A. Orfao ${ }^{2,6}$, and L Escribano ${ }^{1,2,{ }^{*}}$ \\ ${ }^{1}$ Instituto de Estudios de Mastocitosis de Castilla La Mancha (CLMast) Hospital Virgen del Valle \\ Toledo Spain \\ ${ }^{2}$ Red Española de Mastocitosis (REMA) Toledo Spain \\ ${ }^{3}$ Servicio de Dermatología Hospital Ramón y Cajal Madrid Spain \\ ${ }^{4}$ Servicio de Dermatologia Hospital Niño Jesús Madrid Spain \\ ${ }^{5}$ Division of Rheumatology, Allergy and Immunology Virginia Commonwealth University \\ Richmond VA USA \\ ${ }^{6}$ Servicio General de Citometría Centro de Investigación del Cáncer/IBMCC (USAL/CSIC) \\ Departamento de Medicina Universidad de Salamanca Salamanca Spain
}

\section{Abstract}

Background-Despite the good prognosis of pediatric mastocytosis, some patients suffer from severe mast cell (MC) mediator-associated symptoms. The aim of this study was to identify predictors for severe MC mediator release symptoms in children with mastocytosis in the skin (MIS).

\begin{abstract}
Methods-Serum baseline total tryptase (sbT) levels in 111 children with MIS - 80 maculopapular cutaneous mastocytosis/plaque mastocytosis, 22 nodular mastocytosis, and nine diffuse cutaneous mastocytosis - were investigated as a predictive biomarker for the occurrence of $\mathrm{MC}$ mediator-related signs and symptoms within the first 18 months after disease onset.

Results-Twelve children (11\%) who showed extensive cutaneous disease involving $>90 \%$ of body surface area (BSA) suffered from severe symptoms requiring hospitalization, with $(n=5)$ or without $(n=6)$ management in the intensive care unit (ICU) owing to life-threatening complications. The median sbT was significantly $(P<0.001)$ higher in patients with extensive cutaneous disease $v s$ those with $<90 \%$ of BSA involved (45.5 vs $5.2 \mu \mathrm{g} / \mathrm{l}$, respectively), as well as in children with grade 4 (severe mastocytosis-related symptoms requiring emergency therapy and hospitalization) vs those with grade $<4$ ( 46.2 vs $5.2 \mu \mathrm{g} / 1$, respectively). Receiver operating characteristics curve analyses showed that the optimal cutoff $\mathrm{s}$ for $\mathrm{sbT}$ to predict the need for daily antimediator therapy, hospitalization, and the management in an ICU were 6.6, 15.5, and $30.8 \mu \mathrm{g} /$ 1, respectively (sensitivity and specificity of $77 \%$ and $79 \%, 100 \%$ and $95 \%$, and $100 \%$ and $96 \%$, respectively).
\end{abstract}

Conclusions-Increased sbT in association with extensive cutaneous involvement identifies patients at risk for severe $\mathrm{MC}$ activation events in pediatric mastocytosis.

*Correspondence Luis Escribano, MD, PhD, Hospital Virgen del Valle, Instituto de Estudios de, Mastocitosis de Castilla La Mancha, Carretera de Cobisa s/n, 45071 Toledo, Spain. Tel.: +34925269335, Fax: +34925269355, lescribanom@ @escam.jccm.es. 


\section{Keywords}

mast cell; mastocytosis, pediatric; skin; tryptase

Currently, the World Health Organization (WHO) recognizes three major variants of mastocytosis in the skin (MIS): maculopapular cutaneous mastocytosis (MPCM), diffuse cutaneous mastocytosis (DCM), and solitary mastocytoma $(1,2)$. However, other variants of MIS have also been reported, including plaque (PM), nodular (NM) and telangiectatic cutaneous mastocytosis (3); in addition, criteria for the diagnosis of MIS have been proposed (4).

It has been reported that serum baseline total tryptase (sbT) levels $>20 \mu \mathrm{g} / \mathrm{l}$ in pediatric cutaneous mastocytosis $(\mathrm{CM})$ reflect either extensive skin involvement or the possibility of systemic disease (5). Total tryptase levels include both mature and pro forms of tryptase; protryptase is spontaneously and continuously secreted by unstimulated mast cells (MC), while mature tryptase is stored in secretory granules until $\mathrm{MC}$ are activated to degranulate. Nevertheless, the true significance of increased sbT levels at onset of pediatric mastocytosis remains unclear. Although it has been proven that serum mature tryptase (smT) levels transiently increase in most subjects with severe systemic anaphylaxis in association with hypotension (6) and that detectable smT levels with a total tryptase/mature tryptase ratio $\leq 0$ reflect systemic anaphylaxis (7), the exact percentage of patients at risk for severe MC mediator-related symptoms remains unknown.

Here, we investigated the potential association between clinical and laboratory data and the development of MC-related symptoms in a series of 111 children with mastocytosis, within the first 18 months after disease onset. Overall, our results support a direct relationship between sbT levels and the extent of skin involvement in pediatric mastocytosis and a potential role for sbT levels at diagnosis in predicting the clinical severity in our population.

\section{Methods}

\section{Patients}

A total of 111 children - 58 boys (52\%) and 53 girls (48\%) - with a median age of 9 months (range, 1 month-10 years) diagnosed with MIS on the basis of skin biopsy findings according to consensus criteria (4) and referred (within the first 18 months from disease onset) to the Instituto de Estudios de Mastocitosis de Castilla La Mancha (CLMast, Toledo, Spain) between January 2001 and December 2008 were studied. Because of the localized nature of the disease and because systemic MC mediator-related symptoms are usually absent, solitary mastocytoma cases were excluded from the study. The study was approved by the local ethics committee, and only those patients for whom their parents gave an informed consent to participate were enrolled in the study.

Patients were classified according to the type of skin lesions following consensus criteria and the WHO classification $(2,4,8)$ further modified by Hartmann and Henz (3). Extensive skin disease was defined as MIS involving $>90 \%$ of the body surface area (BSA) evaluated as previously described (9). Mastocytosis-related symptoms together with data on specific triggering factors were recorded. Severity was graded according to standard consensus recommendations (4): grade 0 (no symptoms), grade 1 (mild, no therapy required), grade 2 (moderate, kept under control with antimediator-type drugs), grade 3 (severe, not sufficiently controlled with therapy) and grade 4 (severe adverse events that require emergency therapy and hospitalization); in this latter group, the frequency of severe adverse events, total days of hospitalization, and the need for management at an intensive care unit 
(ICU) with vasoactive drugs, orotracheal intubation or blood transfusion support owing to mastocytosis-related life-threatening adverse events were also recorded. According to these criteria, several simplified categories of disease severity are considered for comparison purposes, including grade 4 (hospitalization required) $v s$ grade $\mathfrak{B}$ (hospitalization not required), and, among this latter group, grade $\leq$ (no therapy required) vs grade $\geq 2$ (antimediator therapy required).

\section{Serum mast cell tryptase levels}

SbT levels (CAP; Phadia Diagnostics, Uppsala, Sweden) were measured in all patients at the time of referral. Additionally, smT levels were measured in eight cases by ELISA (sensitivity of $1 \mathrm{ng} / \mathrm{ml}$ ) as described elsewhere (10); in these patients, both serum total and mature tryptase assays were performed in parallel at Virginia Commonwealth University (Richmond, VA, USA).

\section{Bone marrow studies}

Bone marrow (BM) aspirate studies were performed in only three patients at the ICU under general anesthesia and after premedication with $\mathrm{H} 1$ and $\mathrm{H} 2$ antihistamines. $\mathrm{BM}$ smears were stained and analyzed as previously defined (11), and immunophenotypical analysis of BM MC was performed according to the Spanish Network on Mastocytosis (REMA) consensus procedures (12). Detection of somatic activating codon Asp816 $\rightarrow$ Val KIT mutation was performed on genomic DNA, as described elsewhere $(13,14)$.

\section{Management of patients}

Patients were managed according to well-defined guidelines (15-17) that included (i) careful counseling of their parents and close communication with their pediatricians; (ii) strict avoidance of factors triggering acute $\mathrm{MC}$ mediator release; and (iii) usage of protocols for specific situations (e.g., fever, vaccination, teething, and anesthetic procedures).

Treatment consisted of different combinations of drugs, depending on the type and frequency of the symptoms. In all cases with cutaneous symptoms, $0.21 \%$ water-soluble topical sodium cromolyn (18) was used on demand. In patients with grade 1-2 disease, cutaneous symptoms were treated with $\mathrm{H} 1$ antihistamines. For gastric symptoms, $\mathrm{H} 2$ antihistamines were employed, and for abdominal cramping and/or diarrhea, oral disodium cromoglycate was added. Patients with grade $\geq 3$ disease received daily oral disodium cromoglycate and both nonsedating $\mathrm{H} 1$ and $\mathrm{H} 2$ antihistamines, as standard therapy. Sedating $\mathrm{H} 1$ antihistamines, oral glucocorticosteroids, leukotriene antagonists, epinephrine or benzodiazepines, among other drugs, were added when clinically indicated. Moreover, 1 : 1000 zinc sulfate wet-wrap therapy was used for severe cutaneous symptoms with blistering, particularly in DCM patients, in association with daily topical sodium cromolyn and continuous systemic therapy.

\section{Statistical analyses}

The Mann-Whitney $U$ and the chi-square tests were used to assess the statistical significance $(P$-value $\$ 0.05)$ of differences observed between groups for continuous nonparametric and categorical variables, respectively. To identify optimal tryptase cutoff values for highest sensitivity and specificity, receiver operating characteristics (ROC) curve analyses were performed (19). ROC curves plotting sensitivity against 1-specificity were generated and the areas under the curve (AUC) were calculated, in order to measure the accuracy of the test. All statistical analyses were performed with SPSS 15.0 (SPSS, Chicago, IL, USA) and MEDCALC (version 11.4; Medcalc, Mariakerke, Belgium). 


\section{Results}

\section{Clinical findings}

Overall, the median time from disease onset to referral was of 5 months (range, 6 days-17 months). Skin lesions were reported at birth in 17 patients (15\%), while median age at disease onset in the remaining 94 patients was of 3 months (range, 1 day- 8 years). The different subtypes of MIS observed included MPCM in 76/111 (68\%), NM in 22/111 (20\%), DCM in 9/111 (8\%), and PM in 4/111 (4\%) cases. Additionally, Table 1 shows the distribution of the subtypes of cutaneous involvement among the three different categories of the disease (e.g., the checkpoint MIS and the two final diagnoses after BM study, CM, and SM, defined according to consensus criteria). For further comparisons, PM patients were included into the MPCM group, because most of them simultaneously presented plaque and maculopapular skin lesions, and the plaques themselves usually derived from large macules or by the confluence of small patches. Thirteen cases (12\%; all nine DCM, one NM, and three MPCM patients) had extensive cutaneous disease involving $>90 \%$ of BSA. Mutational studies were performed in skin biopsy samples in 19/111 cases (17\%) and the D816V KIT mutation was detected in three of them.

Skin rubbing, heat, and hot bath or shower were the most common triggers for MC-related symptoms (Table 2). Other clinically relevant triggers were irritability, fever, and teething, whereas drugs, food, and vaccination were rarely involved (except among DCM patients) (Table 2). The most frequent symptoms were pruritus (79\%), blistering (55\%), flushing (46\%), diarrhea (21\%), and abdominal cramping (17\%). Twelve children (11\%) - all nine DCM patients, one NM, and two MPCM - had grade 4 disease requiring hospitalization to control severe adverse events (Table 3) - median hospitalization time of 16 days (range, 3200 days) - in association with both extensive cutaneous disease and acute recurrent episodes consisting of pruritus, generalized blistering, and flushing, usually associated with abdominal cramping and/or diarrhea. ICU admission was required in five of these 12 patients (42\%), because of life-threatening adverse events during acute episodes, including upper gastrointestinal bleeding (GIB) in the absence of coagulopathy $(n=4)$, three of them requiring blood transfusion, sepsis secondary to severe cutaneous infections $(n=3)$ caused by Enterobacter cloacae, Staphylococcus epidermidis and Staphylococcus aureus, respectively, and/or hypotension requiring epinephrine $(n=4)$. Noteworthily, in these latter cases, hypotensive episodes were not directly related to sepsis or hypovolemia caused by GIB, but to massive MC mediator release triggered by heat, rubbing, and fever in all cases. Interestingly, sustained hypertension alternating with hypotensive episodes was observed in one patient suffering from extensive MPCM who underwent chronic antihypertensive drug therapy, but with periods when therapy was held owing to hypotensive episodes requiring treatment with epinephrine. Once antihypertensive therapy was discontinued after 2 years of treatment, blood pressure remained at normal levels for six additional years. Only two patients required orotracheal intubation to achieve an adequate sedation; nevertheless, none of the patients showed respiratory distress, cyanosis, or neurological symptoms, including seizures.

\section{Serum tryptase levels}

The median sbT level for the whole group was $6 \mu \mathrm{g} / \mathrm{l}$ (range, 1-213 $\mu \mathrm{g} / \mathrm{l}$ ). A significantly higher $(P<0.001)$ median sbT level was found in cases with extensive cutaneous involvement $v s$ those without (46 vs $5.2 \mu \mathrm{g} / \mathrm{l}$; range, 16-213 vs $1-30 \mu \mathrm{g} / \mathrm{l}$, respectively). In line with these findings, the median sbT level was significantly higher $(P<0.001)$ among $\operatorname{DCM}(45.5 \mu \mathrm{g} / \mathrm{l}$; range, $24-213 \mu \mathrm{g} / \mathrm{l})$ vs both MPCM $(5.1 \mu \mathrm{g} / \mathrm{l}$; range, $1-79 \mu \mathrm{g} / \mathrm{l})$ and NM $(8.1 \mu \mathrm{g} / \mathrm{l}$; range, $2.8-183 \mu \mathrm{g} / \mathrm{l})$ cases, and among NM $v s$ MPCM patients $(P=0.02$; Fig. 1A); such differences were retained even when cases with extensive disease (three MPCM 
patients and one NM child) were excluded from the analysis: median of $7.9 \mu \mathrm{g} / \mathrm{l}$ (range, $2.8-$ $29 \mu \mathrm{g} / \mathrm{l})$ in NM $v s 5.1 \mu \mathrm{g} / \mathrm{l}(\mathrm{range}, 1-30 \mu \mathrm{g} / \mathrm{l})$ in MPCM cases $(P=0.01)$. In line with these observations, sbT levels $>11.4 \mu \mathrm{g} / \mathrm{l}$ and $>20 \mu \mathrm{g} / \mathrm{l}$ were detected in all DCM cases but in only a small proportion of NM (23\% and 9\%, respectively) and MPCM (9\% and 5\%, respectively) patients. Regarding severity of MC mediator release symptoms, the median sbT level was significantly $(P<0.001)$ higher among patients with grade 4 disease than all other children (46 vs $5.2 \mu \mathrm{g} / \mathrm{l}$; range, 16-213 vsl-30 $\mu \mathrm{g} / 1$, respectively; Fig. 1B). Similar results were observed between these groups after excluding grade 4 disease patients who required to be treated in the ICU. Accordingly, a sbT $>20 \mu \mathrm{g} / \mathrm{l}$ was detected in 11/12 (92\%) patients with grade 4 disease $v s 4 / 99(4 \%)$ with grade $\_3$ disease $(P<0.001)$. Among patients with grade $\leq 3$ disease $(n=99)$, the median sbT level was significantly $(P<0.001)$ higher in patients with grade $\geq 2$ than in those with grade $\leq$ disease $(8.1 \mathrm{vs} 4.8 \mu \mathrm{g} / \mathrm{l}$; range, 1.3-30.2 vs 1-28.5 $\mu \mathrm{g} / \mathrm{l}$, respectively). ROC curve analyses (Fig. 2) showed that the most efficient cutoff values for a sbT level to predict grade $\geq 2$ disease, grade 4 , and the need for management in an ICU were $6.6,16$, and $31 \mu \mathrm{g} / 1$, respectively; at these cutoff levels, an AUC of $0.80(P<0.001), 0.99(P<0.001)$, and $0.98(P<0.001)$ was observed with a sensitivity/specificity of $77 \% / 79 \%, 100 \% / 95 \%$, and $100 \% / 96 \%$, respectively. Importantly, no significant differences $(P>0.05)$ were observed according to time from disease onset to referral, among the different groups of patients defined by disease severity. Additionally, measurable smT levels during acute clinical episodes were detected in 7/15 studied acute events occurring in four subjects, the highest smT values corresponding to hypotensive episodes that required treatment with epinephrine in two cases (patients \#7 and \# 10) (Table $4)$.

\section{Screening for systemic mastocytosis}

$\mathrm{BM}$ aspirate samples were obtained in $3 / 5$ children with extensive skin involvement by mastocytosis affecting $>90 \%$ of BSA and increased sbT, who were admitted to the ICU for emergency treatment because of near-fatal MC-related symptoms (patients \#7, \#10, and \#17 in Table 4). According to BM findings, systemic mastocytosis (SM) was ruled out in a DCM case with a sbT of $69 \mu \mathrm{g} / \mathrm{l}$ (patient \#17); conversely, it was confirmed in the other two patients. One of these two latter cases showed spindle-shaped, CD25+ BM MC carrying the D816V KIT mutation in association with MPCM and sbT of $79 \mu \mathrm{g} / \mathrm{l}$ (patient \#10) and he was classified as indolent SM (ISM); the other patient displayed marked BM infiltration with large aggregates of round, well-granulated CD25-negative MC lacking the D816V KIT mutation, consistent with the diagnosis of well-differentiated SM (WDSM) (20-23) in association with NM and sbT of $183 \mu \mathrm{g} / \mathrm{l}$ (patient \#7).

\section{Discussion}

Here, we show that in our cohort of pediatric mastocytosis, sbT levels are associated with the extent of skin involvement and the clinical severity of the disease at presentation; in fact, sbT levels identified patients at risk for suffering severe, even life-threatening MC activation events, as well as those who were more likely to have only mild to moderate symptoms. These findings support future usage of sbT to prospectively develop and efficiently adopt preventive measures in individual patients, including early intensive antimediator therapy.

Here, we confirm previous observations showing that skin rubbing and hot temperatures (24) are the most frequent triggers of MC mediator release symptoms. Interestingly, irritability defined as a hostile behavior characterized by fussing, whining, impatience, anger, and violent rage was found to be a relatively frequent trigger of symptoms in our series, particularly among patients with DCM. Irritability in children is often equated to anxiety in adults, which is known to release neuropeptides from local nerve endings such as corticotropin-releasing hormone, substance $\mathrm{P}$, and neurotensin, leading to $\mathrm{MC}$ activation and 
increased vascular permeability (25-27). Additionally, detailed analysis of our cases showed that extensive cutaneous disease is not restricted to DCM cases, but it is also found in a small subset of NM and MPCM patients. In a retrospective study including 19 pediatric mastocytosis patients, no correlation was found between cutaneous involvement and disease symptoms (9). Conversely, our results indicate that symptoms at disease onset are more severe among DCM vs other MIS groups. Furthermore, although grade 4 disease was most commonly found among DCM, it was also seen in NM and MPCM cases, particularly when skin lesions involved $>90 \%$ BSA. Moreover, life-threatening episodes, secondary to massive $\mathrm{MC}$ mediator release requiring treatment at an ICU, were invariably associated with extensive cutaneous involvement.

Interestingly, hypertension alternating with hypotensive reactions was detected in one patient suffering from extensive MPCM, in whom systemic involvement was confirmed after BM analysis. In line with this observation, it has been reported that chymase (28) converts angiotensin I to the vasoconstrictive peptide angiotensin II, and big endothelins to vasoconstrictive endothelins (e.g., endothelin-1) (29). Thus, because other potential secondary causes for hypertension were excluded, this MC protease could be involved in the genesis of hypertension in this child.

It is well known that patients with extensive cutaneous mastocytosis lesions may have elevated sbT levels $(5,30)$; however, in a series of 19 pediatric mastocytosis cases, sbT levels did not significantly correlate with the extent of skin involvement, but instead, they were only increased in children who had systemic disease (9). In our series, the highest sbT values corresponded to patients with extensive skin involvement and to those expected to have the most severe anaphylactic reactions. Overall, sbT levels $>16$ and $>31 \mu \mathrm{g} / \mathrm{l}$ were associated with grade 4 disease requiring hospitalization and need to be treated at an ICU, respectively. Notably, nearly all children with grade 4 disease had been referred to the CLMast after hospitalization because of severe adverse events. In our series, all but one of these grade 4 disease patients showed dramatic improvement in their MC mediator symptoms after starting antimediator therapy (data not shown). Consequently, early intensive antimediator therapy should probably be given as soon as possible to children identified to be at risk for severe mastocytosis-related anaphylaxis on the basis of the extent of cutaneous involvement and a sbT $>16 \mu \mathrm{g} / \mathrm{l}$. In the only nonresponding case, corresponding to the patient with WDSM, cytoreductive therapy with hydroxyurea was added based on a good response achieved in an adult with progressing WDSM (Escribano L, personal observation) and the safety profile of hydroxyurea in children with sickle cell anemia (31-33). Interestingly, a dramatic response was obtained in this patient with a progressive decrease in clinical symptoms, skin lesions, and the need for intensive antimediator therapy. Careful prospective studies of a large series of patients will reveal the true role of sbT level monitoring and the subtype and extent of MIS in predicting long-term clinical outcome.

Interestingly, BM studies performed in three grade 4 patients who systematically showed $>90 \%$ BSA involvement and sbT > $20 \mu \mathrm{g} / \mathrm{l}$ confirmed the presence of ISM and WDSM (20, 21 ) in two cases, but normal BM findings in the third one. Despite these observations, the actual frequency of systemic involvement in children with MIS cannot be accurately established, because the prediagnostic MIS checkpoint may turn out to be SM upon an eventual BM study performed, when indicated, at an older age. Likewise, whether patients with extensive cutaneous disease in association with systemic involvement are likely to suffer from more severe symptoms than those with extensive disease restricted to skin, while expected, remains unknown. On the other hand, a progressive decrease in sbT over time, in parallel with clinical improvement, was observed in most cases with increased sbT at referral (data not shown). Potential explanations for such decreasing sbT levels in children 
include a decrease in the total MC burden to body mass ratio with age, a decrease in the amount of tryptase per MC that is being spontaneously secreted, decreased MC mediator releasability owing to hormonal changes or antimediator therapy, and a decrease in the total body burden of MC as a consequence of the natural course of the disease. Altogether, these findings suggest that in pediatric mastocytosis, sbT could reflect both the risk of MC activation events and the MC burden, each of which may decline over time. Interestingly, an acute but transient increase in smT levels was detected during severe hypotension episodes in some patients with grade 4 disease, becoming undetectable outside of these acute episodes; these findings are consistent with a release of mature tryptase by degranulation of activated MC. In addition, they support the notion that MC undergo massive degranulation (6) during acute episodes and suggest a potential utility of smT levels to confirm acute anaphylaxis owing to $\mathrm{MC}$ mediator release. By contrast, in other cases, elevation in sbT in the absence of a detectable rise in smT was observed, as also described in mild systemic allergic reactions (in the absence of hypotension) observed after experimental insect sting challenges $(34,35)$ and rush immunotherapy (36). A potential explanation for such apparent discrepancy could be that in such cases, symptoms might result from the activation of small numbers of MC in a specific tissue environment, which produces an insufficient amount of mature tryptase to affect systemic tryptase levels in blood. However, despite treatment with antimediator therapy, sbT levels remained high in the patients here analyzed, consistent with the notion that such increased sbT levels primarily reflect high protryptase levels because protryptases are secreted continuously by unstimulated MC.

\section{Acknowledgments}

Funding

This work was supported by grants from Fondo de Investigación Sanitaria de Castilla la Mancha (FISCAM 2007/36 and FISCAM 2008/46); Ministerio de Sanidad y Asuntos Sociales (FIS PS09/00032); Instituto de Salud Carlos III, Ministerio de Ciencia e Innovación (RTICC RD06/0020/0035-FEDER); Consejería de Educación, Junta de Castilla y León (Grant Grupo de Excelencia GR37) and Fundación Española de Mastocitosis (FEM 2010). L.B. Schwartz is supported by grants from the National Institutes of Health (AI27517 and AI077435).

\section{Abbreviations}

$\begin{array}{ll}\text { AUC } & \begin{array}{l}\text { area under the curve } \\ \text { BM }\end{array} \\ \text { BSA } & \begin{array}{l}\text { bone marrow } \\ \text { CLMast }\end{array} \\ & \begin{array}{l}\text { Instituto de Estudios de Mastocitosis de Castilla La Mancha. The Clinical } \\ \text { Reference Centre of the Spanish Network on Mastocytosis }\end{array} \\ \text { CM } & \text { cutaneous mastocytosis } \\ \text { DCM } & \text { diffuse cutaneous mastocytosis } \\ \text { DNA } & \text { deoxyribonucleic acid } \\ \text { GIB } & \text { gastrointestinal bleeding } \\ \text { ICU } & \text { intensive care unit } \\ \text { ISM } & \text { indolent systemic mastocytosis } \\ \text { KIT } & \text { stem cell growth factor receptor gene } \\ \text { MC } & \text { mast cell } \\ \text { MIS } & \text { mastocytosis in the skin }\end{array}$


MPCM maculopapular cutaneous mastocytosis

NM nodular mastocytosis

PM plaque mastocytosis

REMA Spanish Network on Mastocytosis

ROC receiver operating characteristics

sbT serum baseline total tryptase

SM systemic mastocytosis

smT serum mature tryptase

WDSM well-differentiated systemic mastocytosis

WHO World Health Organization

\section{References}

1. Valent, P.; Horny, HP.; Li, CY.; Longley, BJ.; Metcalfe, DD.; Parwaresch, MR.; Bennett, J. Mastocytosis (Mast cell disease). In: Jaffe, ES.; Harris, NL.; Stein, H.; Vardiman, JW., editors. World Health Organization (WHO) Classification of Tumours. Pathology \& Genetics. Tumours of Haematopoietic and Lymphoid Tissues. Vol. vol. 1. Lyon, France: IARC Press; 2001. p. 291-302.

2. Horny, HP.; Metcalfe, DD.; Bennet, JM.; Bain, BJ.; Akin, C.; Escribano, L.; Valent, P. Mastocytosis. In: Swerdlow, SH.; Campo, E.; Harris, NL.; Jaffe, ES.; Pileri, SA.; Stein, H.; Thiele, J.; Vardiman, JW., editors. WHO Classification of Tumours of Haematopoietic and Lymphoid Tissues. Lyon: IARC; 2008. p. 54-63.

3. Hartmann K, Henz BM. Classification of cutaneous mastocytosis: a modified consensus proposal. Leuk Res. 2002; 26:483-484. [PubMed: 11916523]

4. Valent P, Akin C, Escribano L, Fodinger M, Hartmann K, Brockow K, et al. Standards and standardization in mastocytosis: consensus statements on diagnostics, treatment recommendations and response criteria. Eur J Clin Invest. 2007; 37:435-453. [PubMed: 17537151]

5. Schwartz LB, Sakai K, Bradford TR, Ren S, Zweiman B, Worobec AS, et al. The alpha form of human tryptase is the predominant type present in blood at baseline in normal subjects and is elevated in those with systemic mastocytosis. J Clin Invest. 1995; 96:2702-2710. [PubMed: 8675637]

6. Schwartz LB, Metcalfe DD, Miller JS, Earl H, Sullivan T. Tryptase levels as an indicator of mastcell activation in systemic anaphylaxis and mastocytosis. N Engl J Med. 1987; 316:1622-1626. [PubMed: 3295549]

7. Schwartz LB. Clinical utility of tryptase levels in systemic mastocytosis and associated hematologic disorders. Leuk Res. 2001; 25:553-562. [PubMed: 11377680]

8. Valent P, Horny HP, Escribano L, Longley-BJ J, Li CL, Schwartz LB, et al. Diagnostic Criteria and Classification of Mastocytosis: A Consensus Proposal. Leuk Res. 2001; 25:603-625. [PubMed: 11377686]

9. Brockow K, Akin C, Huber M, Metcalfe DD. Assessment of the extent of cutaneous involvement in children and adults with mastocytosis: Relationship to symptomatology, tryptase levels, and bone marrow pathology. J Am Acad Dermatol. 2003; 48:508-516. [PubMed: 12664011]

10. Enander I, Matsson P, Nystrand J, Andersson A-S, Eklund E, Bradford TR, et al. A new radioimmunoassay for human mast cell tryptase using monoclonal antibodies. J Immunol Methods. 1991; 138:39-46. [PubMed: 2019745]

11. Sperr W, Escribano L, Jordan JH, Schernthaner GH, Kundi M, Horny HP, et al. Morphologic properties of neoplastic mast cells: delineation of stages of maturation and implication for cytological grading of mastocytosis. Leuk Res. 2001; 25:529-536. [PubMed: 11377677]

12. Escribano L, Diaz-Agustin B, López A, López RN, García-Montero A, Almeida J, et al. Immunophenotypic analysis of mast cells in mastocytosis: When and how to do it. Proposals of the 
Spanish network on mastocytosis (REMA). Cytometry B Clin Cytom. 2004; 58:1-8. [PubMed: 14994369]

13. Sotlar K, Escribano L, Landt O, Möhrle S, Herrero S, Torrelo A, et al. One-step detection of c-kit point mutations using PNA-mediated PCR-clamping and hybridization probes. Am J Pathol. 2003; 162:737-746. [PubMed: 12598308]

14. Garcia-Montero AC, Jara-Acevedo M, Teodosio C, Sanchez ML, Nunez R, Prados A, et al. KIT mutation in mast cells and other bone marrow haematopoietic cell lineages in systemic mast cell disorders. A prospective study of the Spanish Network on Mastocytosis (REMA) in a series of 113 patients. Blood. 2006; 108:2366-2372. [PubMed: 16741248]

15. Escribano L, Akin C, Castells M, Orfao A, Metcalfe D. Mastocytosis: Current concepts in diagnosis and treatment. Ann Hematol. 2002; 81:677-690. [PubMed: 12483363]

16. Escribano L, Akin C, Castells M, Schwartz LB. Current options in the treatment of mast cell mediator-related symptoms in mastocytosis. Inflamm Allergy Drug Targets. 2006; 5:61-77. [PubMed: 16613565]

17. Castells M, Metcalfe DD, Escribano L. Diagnosis and treatment of cutaneous mastocytosis in children: practical recommendations. Am J Clin Dermatol. 2011; 12:259-270. [PubMed: 21668033]

18. Moore C, Ehlayel MS, Junprasert J, Sorensen RU. Topical sodium cromoglycate in the treatment of moderate-to-severe atopic dermatitis. Ann Allergy Asthma Immunol. 1998; 81:452-458. [PubMed: 9860040]

19. Metz CE. Basic principles of ROC analysis. Semin Nucl Med. 1978; 8:283-298. [PubMed: 112681]

20. Akin C, Escribano L, Núñez R, García-Montero A, Angulo M, Orfao A, et al. Well-Differentiated Systemic Mastocytosis: A New Disease Variant with Mature Mast Cell Phenotype and Lack of Codon 816 c-Kit Mutations. J Allergy Clin Immunol. 2004; 113:S327.

21. Akin C, Fumo G, Yavuz AS, Lipsky PE, Neckers L, Metcalfe DD. A novel form of mastocytosis associated with a transmembrane c-kit mutation and response to imatinib. Blood. 2004; 103:32223225. [PubMed: 15070706]

22. Teodosio C, Garcia-Montero AC, Jara-Acevedo M, Sanchez-Munoz L, varez-Twose I, Nunez R, et al. Mast cells from different molecular and prognostic subtypes of systemic mastocytosis display distinct immunophenotypes. J Allergy Clin Immunol. 2010; 125:719-726. [PubMed: 20061010]

23. Sanchez-Munoz L, Alvarez-Twose I, Garcia-Montero AC, Teodosio C, Jara-Acevedo M, Pedreira $\mathrm{CE}$, et al. Evaluation of the WHO criteria for the classification of patients with mastocytosis. Mod Pathol. 2011; 24:1157-1168. [PubMed: 21552214]

24. Brockow K, Jofer C, Behrendt H, Ring J. Anaphylaxis in patients with mastocytosis: a study on history, clinical features and risk factors in 120 patients. Allergy. 2008; 63:226-232. [PubMed: 18186813]

25. Theoharides TC, Donelan JM, Papadopoulou N, Cao J, Kempuraj D, Conti P. Mast cells as targets of corticotropin-releasing factor and related peptides. Trends Pharmacol Sci. 2004; 25:563-568. [PubMed: 15491778]

26. Donelan J, Boucher W, Papadopoulou N, Lytinas M, Papaliodis D, Dobner P, et al. Corticotropinreleasing hormone induces skin vascular permeability through a neurotensin-dependent process. Proc Natl Acad Sci U S A. 2006; 103:7759-7764. [PubMed: 16682628]

27. Asadi S, Alysandratos KD, Angelidou A, Miniati A, Sismanopoulos N, Vasiadi M, et al. Substance P (SP) Induces Expression of Functional Corticotropin-Releasing Hormone Receptor-1 (CRHR-1) in Human Mast Cells. J Invest Dermatol. 2012; 132:324-329. [PubMed: 22089831]

28. Caughey GH, Raymond WW, Wolters PJ. Angiotensin II generation by mast cell $\alpha$ - and $\beta$ chymases. Biochim Biophys Acta Protein Struct Mol Enzymol. 2000; 1480:245-257.

29. Nakano A, Kishi F, Minami K, Wakabayashi H, Nakaya Y, Kido H. Selective conversion of big endothelins to tracheal smooth muscle-constricting 31-amino acid-length endothelins by chymase from human mast cells. J Immunol. 1997; 159:187-192.

30. Heide R, van Doorn K, Mulder PG, Van Toorenenbergen AW, Beishuizen A, De GH, et al. Serum tryptase and SCORMA (SCORing MAstocytosis) Index as disease severity parameters in 
childhood and adult cutaneous mastocytosis. Clin Exp Dermatol. 2008; 34:462-468. [PubMed: 19077102]

31. Hankins JS, Ware RE, Rogers ZR, Wynn LW, Lane PA, Scott JP, et al. Long-term hydroxyurea therapy for infants with sickle cell anemia: the HUSOFT extension study. Blood. 2005; 106:22692275. [PubMed: 16172253]

32. Ware RE. How I use hydroxyurea to treat young patients with sickle cell anemia. Blood. 2010; 115:5300-5311. [PubMed: 20223921]

33. McGann PT, Flanagan JM, Howard TA, Dertinger SD, He J, Kulharya AS, et al. Genotoxicity associated with hydroxyurea exposure in infants with sickle cell anemia: Results from the BABYHUG phase III clinical trial. Pediatr Blood Cancer. 2011 00:00-00.

34. Van der Linden P-WG, Hack CE, Poortman J, Vivié-Kipp YC, Struyvenberg A, Van der Zwan JK. Insect-sting challenge in 138 patients: Relation between clinical severity of anaphylaxis and mast cell activation. J Allergy Clin Immunol. 1992; 90:110-118. [PubMed: 1629497]

35. Schwartz LB, Bradford TR, Rouse C, Irani A-M, Rasp G, Van der Zwan JK, et al. Development of a new, more sensitive immunoassay for human tryptase: Use in systemic anaphylaxis. J Clin Immunol. 1994; 14:190-204. [PubMed: 7929694]

36. Vegh AB, George KC, Lotfi-Emran S, Butler NE, Schwartz LB. Total tryptase levels indicate risk for systemic reactions to rush immunotherapy and mast cell activation. Ann Allergy Asthma Immunol. 2011; 106:342-343. [PubMed: 21457884] 

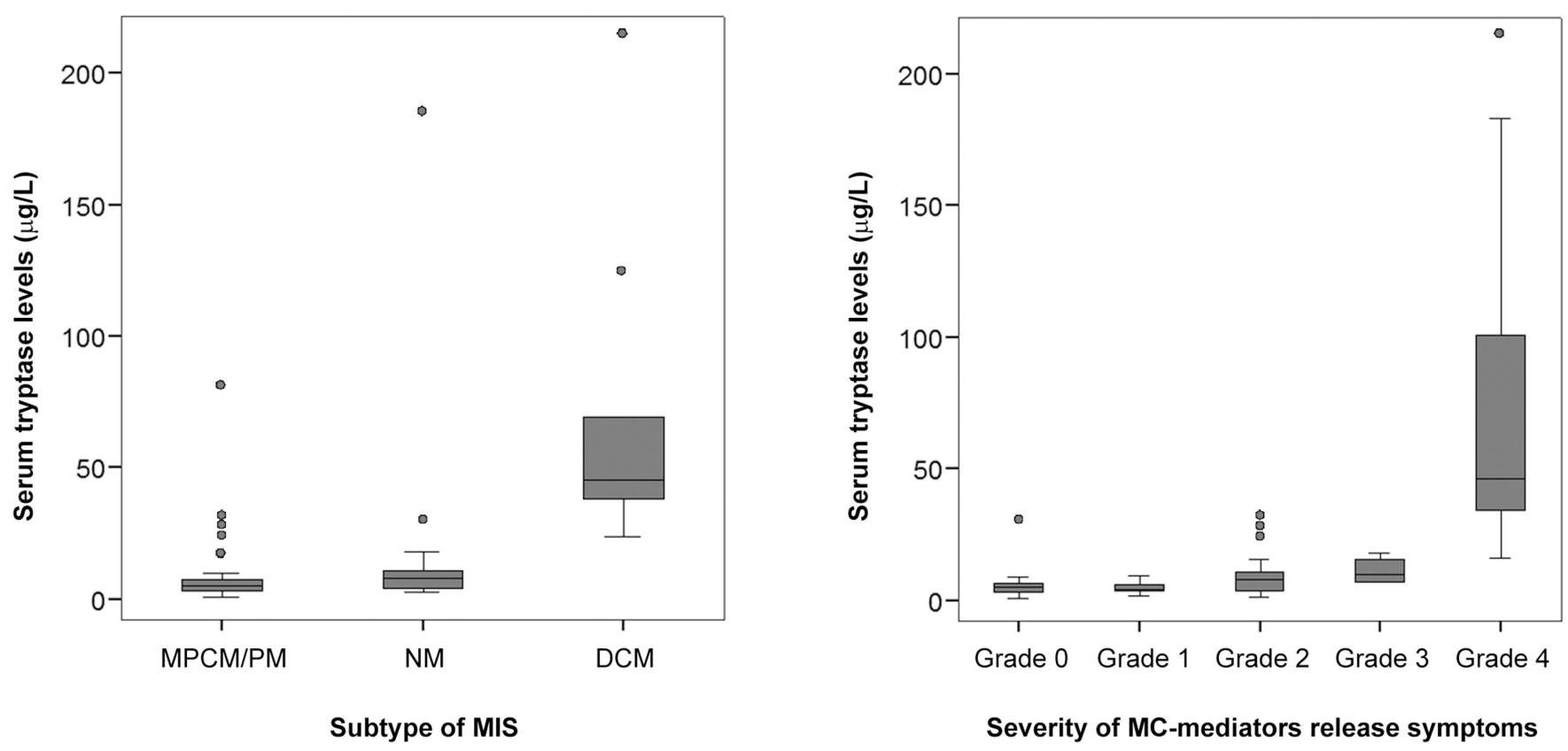

Figure 1.

Serum baseline total tryptase (sbT) levels detected at patient referral among the different subtypes of mastocytosis in the skin (MIS) (panel A) and among the different groups of MIS established according to the clinical severity of anaphylaxis (panel B). Higher baseline sbT levels were detected in panel A, DCM $v s$ both NM $(P<0.001)$ and MPCM $(P<0.001)$, NM $v s \operatorname{MPCM}(P=0.02)$; panel $\mathrm{B}$, grade 4 patients $v s$ all the other groups $(P<0.001)$. 

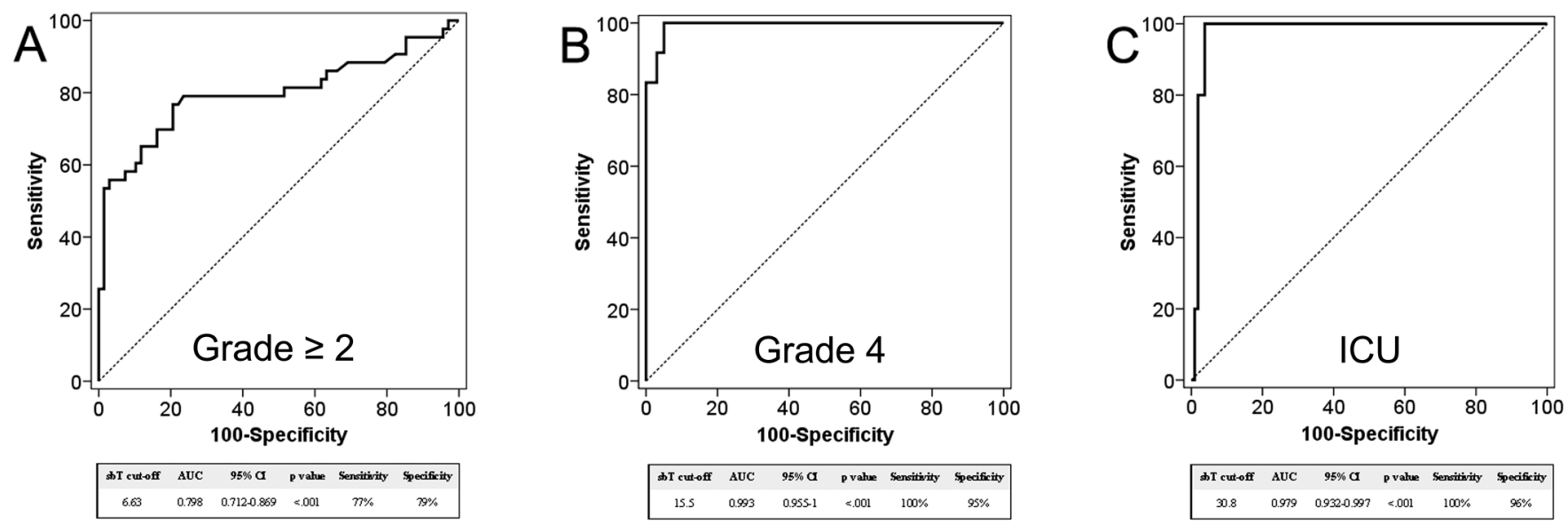

Figure 2.

Receiver operating characteristics (ROC) curves searching for the utility of sbT levels for the identification of patients with grade $\geq 2$ (panel A), grade 4 (panel B) disease and those who needed to be treated in an intensive care unit (panel C). The optimal sbT cutoff values detected in each case were of $6.6 \mu \mathrm{g} / \mathrm{l}$ (panel A), $16 \mu \mathrm{g} / \mathrm{l}$ (panel B), and $31 \mu \mathrm{g} / \mathrm{l}$ (panel C). AUC, area under the curve; CI, confidence interval. 


\section{Table 1}

Distribution of the different patterns of cutaneous involvement in MIS, CM and SM patients.

\begin{tabular}{lccc}
\hline & MIS $^{*}(\mathbf{n = 1 2})$ & $\mathbf{C M}^{*}(\mathbf{n = 9 7})$ & $\mathbf{S M}^{*}(\mathbf{n = 2})$ \\
\hline MPCM/PM & $3(25)$ & $76(78)$ & $0(0)$ \\
NM & $1(8)$ & $20(21)$ & $1(50)$ \\
DCM & $8(67)$ & $1(1)$ & $1(50)$ \\
\hline
\end{tabular}

Results expressed as number of cases (\%).

MIS, mastocytosis in the skin; CM, cutaneous mastocytosis; SM, systemic mastocytosis; MPCM, maculopapular cutaneous mastocytosis; PM, plaque mastocytosis; NM, nodular mastocytosis; DCM, diffuse cutaneous mastocytosis.

*According to standardized consensus recommendations (4): MIS is a pre-diagnostic checkpoint corresponding to patients who have serum tryptase levels between 20 and $100 \mu \mathrm{g} / \mathrm{L}$ in the absence of a BM study; CM include patients with serum tryptase levels $<20 \mu \mathrm{g} / \mathrm{L}$ and those with proven absence of BM infiltration; SM corresponds to patients with proven BM infiltration. 
Table 2

Clinical characteristics of patients $(n=111)$ distributed according to the specific subvariants of mastocytosis in the skin.

\begin{tabular}{|c|c|c|c|c|}
\hline & MPCM/PM (n=80) & NM (n=22) & $\operatorname{DCM}(\mathbf{n}=9)$ & $p$ value \\
\hline \multicolumn{5}{|l|}{ Demographics } \\
\hline Male & $39(49)$ & $15(68)$ & $4(44)$ & NS \\
\hline Age $^{*}$ at onset ${ }^{1}$ & $3(0-106)$ & $2(0-9)$ & $3(0-8)$ & NS \\
\hline Age $^{*}$ at referral ${ }^{1}$ & $11(1-114)$ & $6(1-23)$ & $6(3-25)$ & NS \\
\hline Time $^{*}$ from onset to referral ${ }^{1}$ & $7(0-17)$ & $4(0-15)$ & $5(0-16)$ & NS \\
\hline \multicolumn{5}{|l|}{ Areas of skin involved } \\
\hline Trunk & $76(95)$ & $22(100)$ & $9(100)$ & NS \\
\hline $\mathrm{P} / \mathrm{D}$ extremities & $62(77) / 29(36)$ & $21(95) / 11(50)$ & $9(100) / 9(100)$ & $\mathrm{NS} / .04$ \\
\hline Neck & $45(56)$ & $16(73)$ & $9(100)$ & .02 \\
\hline Scalp & $31(39)$ & $13(59)$ & $9(100)$ & .001 \\
\hline \multicolumn{5}{|l|}{ Extension of cutaneous disease } \\
\hline$>90 \%$ of BSA & $3(4)$ & $1(4)$ & $9(100)$ & $<.001$ \\
\hline \multicolumn{5}{|l|}{ Type of MC-related symptoms } \\
\hline Blistering & $35(44)$ & $17(77)$ & $9(100)$ & .003 \\
\hline Pruritus & $59(74)$ & $20(91)$ & $9(100)$ & NS \\
\hline Flushing & $30(37)$ & $12(54)$ & $9(100)$ & .001 \\
\hline Abdominal cramping & $14(17)$ & $1(4)$ & $4(44)$ & .04 \\
\hline Diarrhea & $12(15)$ & $6(27)$ & $5(56)$ & .01 \\
\hline Hypotension & $1(1)$ & $1(4)$ & $2(22)$ & .03 \\
\hline GIB & $1(1)$ & $1(4)$ & $2(22)$ & .03 \\
\hline \multicolumn{5}{|l|}{${\text { Grading of symptoms }{ }^{\dagger}}^{\dagger}$} \\
\hline Grade 0 & $21(26)$ & $2(9)$ & $0(0)$ & NS \\
\hline Grade 1 & $35(44)$ & $10(45)$ & $0(0)$ & .007 \\
\hline Grade 2 & $19(24)$ & $7(32)$ & $0(0)$ & NS \\
\hline Grade 3 & $3(4)$ & $2(9)$ & $0(0)$ & NS \\
\hline Grade 4 & $2(2)$ & $1(4)$ & $9(100)$ & $<.001$ \\
\hline \multicolumn{5}{|l|}{ Triggers for symptoms } \\
\hline Skin friction & $47(59)$ & $18(82)$ & $9(100)$ & .02 \\
\hline Heat and/or hot water & $46(57)$ & $19(86)$ & $9(100)$ & .02 \\
\hline Cold & $5(6)$ & $2(9)$ & $2(22)$ & NS \\
\hline Exercise & $2(2)$ & $1(4)$ & $0(0)$ & NS \\
\hline Food ${ }^{*}$ & $4(5)$ & $1(4)$ & $1(11)$ & NS \\
\hline $\operatorname{Drugs} s$ & $3(4)$ & $0(0)$ & $1(11)$ & NS \\
\hline Vaccines & $3(4)$ & $2(9)$ & $4(44)$ & .002 \\
\hline
\end{tabular}




\begin{tabular}{lcccc}
\hline & MPCM/PM $(\mathbf{n}=\mathbf{8 0})$ & NM $(\mathbf{n = 2 2})$ & DCM (n=9) & p value \\
\hline Irritability & $21(26)$ & $6(27)$ & $4(44)$ & NS \\
Teething & $12(15)$ & $8(36)$ & $3(33)$ & NS \\
Fever & $16(20)$ & $7(32)$ & $8(89)$ & $<.001$ \\
\hline
\end{tabular}

Results expressed as number ot cases (\%) and as ${ }^{1}$ median (range). P value reters to compansions between DCM and all the other cases.

MC, mast cell; MPCM, maculopapular cutaneous mastocytosis; PM, plaque mastocytosis; NM, nodular mastocytosis; DCM, diffuse cutaneous mastocytosis; P, proximal; D, distal; BSA, body surface area; GIB, gastrointestinal bleeding; NS, non-significant.

Expressed in months.

${ }^{\dagger}$ According to standardized consensus recommendations (reference \#4): grade 0 (no symptoms), grade 1 (mild, no therapy required), grade 2 (moderate, kept uder control with antimediator-type drugs), grade 3 (severe, not sufficiently controlled with therapy) and grade 4 (severe adverse event, requires emergency therapy and hospitalization).

${ }^{*}$ Culprit foods (and the corresponding symptoms) included prawn (angioedema), banana (pruritus), kiwi and tomato (pruritus), pig ribs (hives and pruritus), bread roll (pruritus) and chocolate, egg and lentil (hives, flushing, blistering and diarrhea). No specific IgE against the involved foods were detected in any case.

${ }^{\S}$ Culprit drugs (and the corresponding symptoms) included dipyrone and diclofenac (hives, pruritus and angioedema), ibuprofen (hives), polivitaminic complex (pruritus) and ibuprofen (hives and angioedema). 


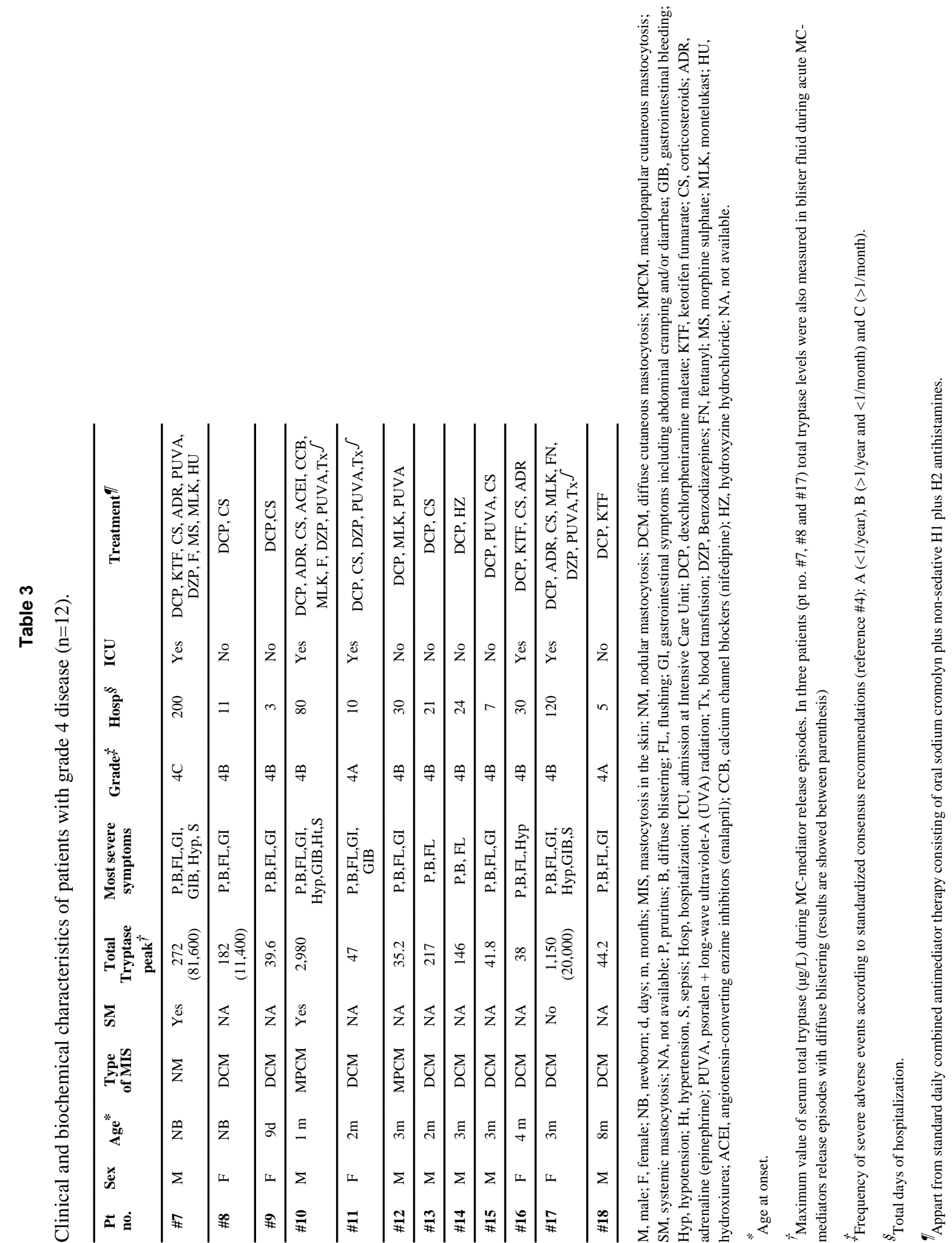




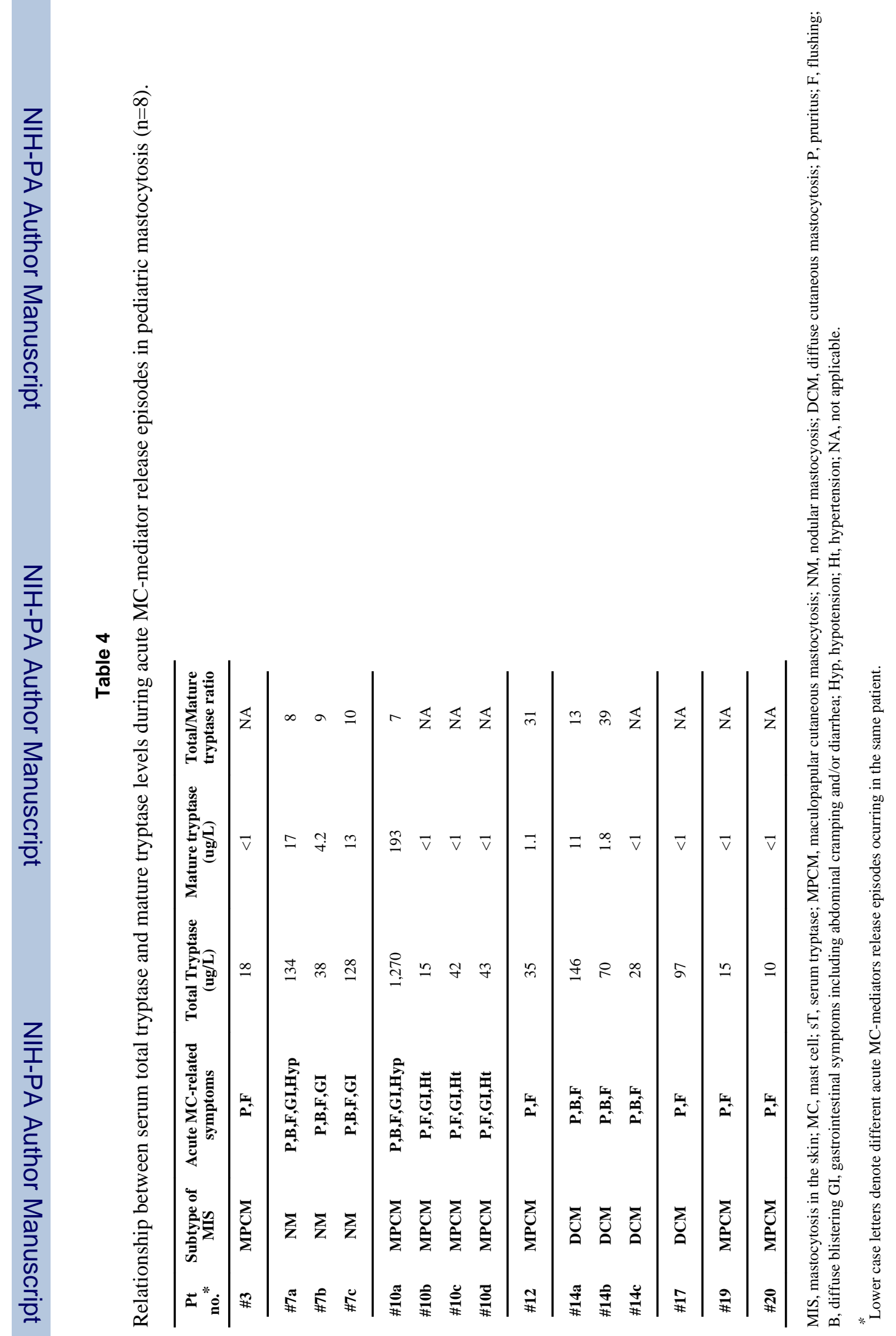

